\title{
Assessment of Dental Caries and Oral Health Challenges of School-Age Children in Rhino Camp Refugee Settlements in Arua, Uganda
}

\author{
Robert Kagabo, PhD, MSW, MPH ${ }^{1 *}$, Tejinder P Singh, BDS, MDS, $M P H^{1}$, Caren J Frost, PhD, $M P H^{2}$ and \\ Lisa H Gren, PhD, MSPH ${ }^{1}$
}

${ }^{1}$ Department of Family \& Preventive Medicine, Division of Public Health, University of Utah School of Medicine, USA

${ }^{2}$ College of Social Work, and Division of Public Health, University of Utah, USA

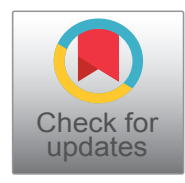

*Corresponding author: Robert Kagabo, PhD, MSW, MPH, Department of Family \& Preventive Medicine, and Division of Public Health, University of Utah School of Medicine, Salt Lake City UT, USA, Tel: 801-581-8068

\begin{abstract}
Background: Oral health remains a global public health concern. Limited available research indicates there is a link among poor oral health, socio-economic status, and other health disparities. However the oral health challenges among refugee children in African refugee camps has had negligible exploratory attention.
\end{abstract}

Aim: To assess dental caries and other oral health challenges of primary school-age children in Rhino Camp Refugee Settlements in Arua, Uganda.

Methods: Two primary schools were selected from Rhino Camp Refugee Settlements in Arua, Uganda. Participants were from only one class at each of the selected schools. This cross-sectional study was completed in June 2017. Using the World Health Organization guidelines, we calculated the decayed, missing, filled teeth (DMFT) index.

Results: There were 177 primary school-age students 8-17 years old, with adult teeth. $51.4 \%$ of the participants were females, and $48.6 \%$ were males. Of all participants, 165 $(93.2 \%)$ had missing or decayed teeth. The mean DMFT index was 4.78 among males and 5.54 among females.

Conclusion: Oral health is a concern for people living in refugee camps. The observed high DMFT prevalence among school-age children calls for aggressive, evidencebased interventions including health promotion education. Oral health is linked to other health issues and evidencebased interventions will likely also improve the general health of school-age children in these refugee camps.

\section{Keywords}

Children's oral health, Refugee camps

\section{Introduction}

As of 2017, there were approximately 65 million displaced persons worldwide with 22.5 million recognized as refugees [1]. The high level of global movement has prompted the United Nations High Commissioner for Refugees (UNHCR) to launch global action plans that prioritize the health needs for refugee populations [2-4].

In 2017, Uganda was host to approximately 1.2 million refugees, mostly from South Sudan [5]. Uganda, a signatory to the above mentioned action plans, has increasing refugee populations residing in its Rhino and Bidi-Bidi refugee settlement camps in Arua [5]. Healthcare services are under the umbrella of the UNHCR, and are global priorities for hosting countries, such as Uganda [4]. Refugees often have neglected oral health, which results in untreated diseases in the form of caries, periodontal problems and pain [6]. Traumatic injuries to orofacial structures are also common among those with refugee backgrounds [7]. Deficient oral health compromises overall systemic physical health, nutrition, and is associated with other chronic diseases such as cardiovascular diseases $[6,8,9]$. Thus, improving 
oral health for refugee populations should facilitate better health outcomes.

The World Health Organization (WHO) developed a guide for implementing population-level oral health surveys, but these surveys are not often conducted with refugee populations $[10,11]$. Oral health assessments begin by determining the decayed teeth $(D)$, teeth extracted or missing due to dental decay (M), and teeth filled due to dental decay (F). The combined count of teeth with problems is the DMFT index. The DMFT is coupled with non-invasive observational measures of bleeding gums to assess gingival and periodontal health to provide a clear picture of the oral health of individuals and communities [12]. The objective of this feasibility study was to assess the oral health experience of school-aged children living in Rhino camp refugee settlements in Arua, Uganda and compare the data with reference populations from the host country and refugee's country of origin.

\section{Methods}

A cross-sectional study was conducted to assess the oral health experience of children attending primary school in Rhino Camp Refugee Settlements in Uganda. Two primary school classes were selected, by convenience, with participants from primary grade three at one school and primary grade seven at the other school. Participants were male and female students attending the two chosen classes at the two schools on the day of data collection. Using WHO's guidelines and standardized oral health assessment forms [13], the research team collected data to calculate the decayed, missing, filled teeth (DMFT) index on 177 children attending primary school. Research assistants were trained and certified regarding how to perform the DMFT assessments by one of the investigators who is a dentist. The consent process was explained separately to science and head teachers one to two days before the assessments were completed. The research team also met with community members before the assessment to explain the educational and research processes. On the assessment days, the research team provided a brief introduction to oral health to the students in class during the science hour and before the assessment, followed by an informed consent discussion. The students were allowed to opt out if they chose to do so. While research team members examined students, one of the team members continued to give the basic oral health hygiene lesson. During the basic oral health lesson, students were allowed to ask questions about oral health as they wished. Two students at a time interacted with the research team for the assessment. Students received a free tooth brush following the examination of their oral cavity. The University of Utah's Institutional Review Board provided ethical clearance for the study. Descriptive statistics were computed using Stata, version 12.0 (College Station, TX, USA).

\section{Findings}

The total number of participants included in this assessment was 177 , of whom $51.4 \%$ were female. The observed mean number of decayed teeth (D) was 3.93 for females and 3.12 for males. Mean DMFT was 5.54 among females and 4.78 among males. T-test results did not show any significant differences in DMFT for females and males, $p=0.209$. Our analysis of variance (ANOVA) for DMFT by age group showed that a difference exists among age groups, $p<0.001$. The proportion of children with decayed or missing teeth was lower in younger children (82.0\% for ages 8-11) than in older children (100.0\% for ages $12-14$ and $98.2 \%$ for ages $15-17$ ). The mean DMFT ranged from 3.59 to 6.38 (Table 1 ).

\section{Discussion}

Global migration, whether forced or voluntary, is at an all-time high, creating a crisis for resettlement and human rights agencies especially in the sectors of food, shelter and health [14]. The conditions of displacement limit the attention of the refugee population towards maintaining optimal personal health, and health systems in host countries struggle to provide required health care $[6,15]$. In the past, community-level primary oral health care interventions designed to meet the needs of the population have been successfully implemented [16].

Table 1: Oral health of children aged 8-17 years attending primary school in rhino camp refugee settlements in Arua, Uganda (June, 2017).

\begin{tabular}{|c|c|c|c|c|c|c|}
\hline \multirow[t]{2}{*}{$N=177$} & \multirow[t]{2}{*}{$\%$ Affected } & \multicolumn{4}{|c|}{ Mean } & \multirow[t]{2}{*}{ p-value } \\
\hline & & D & M & $\mathbf{F}$ & DMFT & \\
\hline \multicolumn{6}{|l|}{ Gender/Sex } & \multirow[t]{3}{*}{0.209} \\
\hline Females $(n=91)$ & 92.3 & 3.93 & 1.60 & 0 & $5.54^{*}$ & \\
\hline Males $(n=86)$ & 94.2 & 3.12 & 1.66 & 0 & 4.78 & \\
\hline \multicolumn{6}{|l|}{ Age (Years) } & \multirow[t]{4}{*}{$<0.001$} \\
\hline $8-11(n=61)$ & 82.0 & 2.80 & 0.79 & 0 & 3.59 & \\
\hline $12-14(n=61)$ & 100.0 & 4.00 & 2.38 & 0 & 6.38 & \\
\hline $15-17(n=55)$ & 98.2 & 3.84 & 1.75 & 0 & $5.58^{*}$ & \\
\hline
\end{tabular}

*Off due to rounding. 
Table 2: DMFT Scores reported in other global settings (2005-2018).

\begin{tabular}{|c|c|c|c|c|}
\hline Country (Author \& Year) & $\begin{array}{l}\text { Study } \\
\text { size (n) }\end{array}$ & $\begin{array}{l}\text { Age range } \\
\text { (Years) }\end{array}$ & $\begin{array}{l}\text { Percent with } \\
\text { tooth decay }\end{array}$ & $\begin{array}{l}\text { DMFT index } \\
\text { Mean (SD) }\end{array}$ \\
\hline Germany (Goetz, et al. [21]) & 102 & $16-64$ & 86.3 & $6.89(5.5)$ \\
\hline \multirow{2}{*}{$\begin{array}{l}\text { Algeria (Almerich-Silla, Montiel-Company, \& Ruiz- } \\
\text { Miravet, et al. [22]) }\end{array}$} & 360 & $6-7$ & 47.2 & 0.48 \\
\hline & 212 & $11-13$ & 63.2 & 1.69 \\
\hline Uganda (Batwala, Mulogo, \& Arubaku [17]) & 437 & $5-12$ & * & $1.5(0.8)$ \\
\hline \multirow[t]{2}{*}{ Uganda (Kutesa, et al. [23]) } & 1.230 & $11-13$ & 32.5 & 0.73 \\
\hline & 648 & $35-44$ & 66.7 & 4.71 \\
\hline \multirow[t]{2}{*}{ Uganda (Muwazi, et al. [18]) } & 696 & 12 & 40.0 & 0.9 \\
\hline & 396 & $35-44$ & 63.0 & 3.4 \\
\hline \multirow[t]{7}{*}{ Tanzania** (Beltrán, et al. [24]) } & 99 & $4-5$ & $B=64.0$ & $B=3.64$ \\
\hline & & & $C=36.7$ & $C=1.27$ \\
\hline & 101 & $12 \& 15$ & $B=31.4$ & $B=0.76$ \\
\hline & & & $C=26.0$ & $C=0.62$ \\
\hline & & & $\mathrm{T}=66.0$ & $\mathrm{~T}=2.72$ \\
\hline & 103 & 20 and above & $B=69.8$ & $B=3.36$ \\
\hline & & & $C=44.0$ & $C=1.70$ \\
\hline
\end{tabular}

"Not reported in the study; ${ }^{* *} \mathrm{~B}=$ Burundian refugees; $\mathrm{C}=$ Congolese refugees; $\mathrm{T}=$ Tanzanians living in western district of Kigoma.

This feasibility study provided a summary assessment of dental caries of school-aged children to serve as a planning tool for broader community level oral health interventions. A high percentage of males and females were affected with dental caries (92.3 and 94.2 , respectively). However, in our study, gender difference was not significant, as has been reported elsewhere $[17,18]$. Overall, the DMFT score at all ages was substantially higher than reported values in the region and from other global settings of a similar socioeconomic demographic (Table 2). The values were also higher than the recommended goal of having fewer than $50 \%$ of children with caries, as announced by the WHO and Federation of Dentistry International [19]. Thus, when compared, there is an obvious and urgent need for prevention and treatment of oral disease in the Rhino camp refugee settlements. Urgency of treatment needs is highlighted by the 0 score for fillings (F) among children with a clear history of dental caries. Several studies with similar findings have been reported outside of the camp environment in Uganda, prompting school-based interventions for oral healthcare $[17,18,20]$. Similar efforts are required in the Rhino camp refugee settlements.

\section{Conclusions}

Oral health is a concern for people living in refugee camps. The observed high DMFT prevalence among school-age children in Rhino Camp Refugee Settlements in Arua, Uganda calls for aggressive, evidence-based interventions including health promotion education. Oral health is linked to other health issues and evidencebased interventions will likely improve the general health of school-age children in these refugee camps. For this population with greater health disparities, these findings provide a foundation and need for healthcare providers to collaborate with community advocacy groups such as community health educators to implement interventions.

\section{Acknowledgement}

Alex Adaku, MD, Alfred Alumai, Ph.D, Brinley CaseResearch Assistant, Meagan Porter-Research Assistant.

\section{References}

1. Atiyeh BS, Gunn SWA (2017) Refugee camps, fire disasters and burn injuries. Ann Burns Fire Disasters 30: 214-217.

2. Abbas M, Aloudat T, Bartolomei J, Carballo M, DurieuxPaillard S, et al. (2018) Migrant and refugee populations: A public health and policy perspective on a continuing global crisis. Antimicrob Resist Infect Control 7: 113.

3. Bozorgmehr K, Razum O (2016) Forced migration and global responsibility for health comment on "Defining and acting on global health: The case of Japan and the refugee crisis". Int J Health Policy Manag 6: 415-418.

4. Manisha T (2017) Turning the comprehensive refugee response framework into reality. FMR 56: 69-72.

5. Trombola FMN (2017) Uganda's 1.2 million refugees at a glance. Daily Monitor.

6. Keboa MT, Hiles N, Macdonald ME (2016) The oral health of refugees and asylum seekers: A scoping review. Global Health. 12: 59 .

7. Lamb CE, Whelan AK, Michaels C (2009) Refugees and oral health: Lessons learned from stories of Hazara refugees. Aust Health Rev 33: 618-627.

8. Carramolino-Cuellar E, Tomas I, Jimenez-Soriano Y (2014) Relationship between the oral cavity and cardiovascular diseases and metabolic syndrome. Med Oral Patol Oral Cir Bucal 19: e289-e294.

9. Cronin A (2009) Periodontal disease is a risk marker for coronary heart disease? Evid Based Dent 10: 22. 
10. Riggs E, Rajan S, Casey S, Kilpatrick N (2017) Refugee child oral health. Oral Dis 23: 292-299.

11. Tobin AO, Ajayi IO (2017) Common oral conditions and correlates: An oral health survey in Kwara State Nigeria. BMC Res Notes 10: 568.

12. Moreau AM, Hennous F, Dabbagh B, Ferraz Dos Santos B (2018) Oral health status of refugee children in montreal. J Immigr Minor Health.

13. Shah N, Mathur VP, Kant S, Gupta A, Kathuria V, et al (2017) Prevalence of dental caries and periodontal disease in a rural area of Faridabad District, Haryana, India. Indian J Dent Res 28: 242-247.

14. Garkisch M, Heidingsfelder J, Beckmann M (2017) Third sector organizations and migration: A systematic literature review on the contribution of third sector organizations in view of flight, migration and refugee crises. Voluntas: IJVNO 28: 1839-1880.

15. Kotsiou OS, Kotsios P, Srivastava DS, Kotsios V, Gourgoulianis KI, et al. (2018) Impact of the refugee crisis on the greek healthcare system: A long road to ithaca. Int $\mathrm{J}$ Environ Res Public Health 15: 1790.

16. Mickenautsch S, Rudolph MJ, Ogunbodede EO, Chikte UM (1999) Oral health among liberian refugees in Ghana. East Afr Med J 76: 206-211.

17. Batwala V, Mulogo EM, Arubaku W (2007) Oral health status of school children in Mbarara, Uganda. Afr Health
Sci 7: 233-238.

18. Muwazi LM, Rwenyonyi CM, Tirwomwe FJ, Ssali C, Kasangaki A, et al. (2005) Prevalence of oral diseases/ conditions in Uganda. Afr Health Sci 5: 227-233.

19. Prasai Dixit L, Shakya A, Shrestha M, Shrestha A (2013) Dental caries prevalence, oral health knowledge and practice among indigenous Chepang school children of Nepal. BMC Oral Health 13: 20.

20. Macnab A, Kasangaki A (2012) 'Many voices, one song': A model for an oral health programme as a first step in establishing a health promoting school. Health Promot Int 27: 63-73.

21. Goetz K, Winkelmann W, Steinhauser J (2018) Assessment of oral health and cost of care for a group of refugees in Germany: A cross-sectional study. BMC Oral Health 18: 69.

22. Almerich-Silla JM, Montiel-Company JM, Ruiz-Miravet A (2008) Caries and dental fluorosis in a western Saharan population of refugee children. Eur J Oral Sci 116: 512-517.

23. Kutesa A, Kasangaki A, Nkamba M, Muwazi L, Okullo I, et al. (2015) Prevalence and factors associated with dental caries among children and adults in selected districts in Uganda. Afr Health Sci 15: 1302-1307.

24. Beltrán E, Cherrett $H$, Hobdell $M$, Jaramillo $F$, Robison V (2006) Tanzania site assessments: Refugee camps. Tanzania: Faculty of Dentistry at Muhimbili University. 